\title{
LA IMAGEN DE ARAGÓN EN LOS LIBROS DE TEXTO DE EDUCACIÓN PRIMARIA
}

\author{
E. Climent López, E. García Pascual y E. Ruiz Budría \\ Universidad de Zaragoza
}

\begin{abstract}
Resumen: En el artículo se realiza un estudio de los libros de texto de educación primaria utilizados en los colegios aragoneses, con el objetivo de desvelar la imagen de Aragón que transmiten a los escolares. El análisis realizado permite concluir que todos los libros de texto siguen el modelo académico clásico, diferenciándose por adoptar, en unos casos, un enfoque puramente informativo-descriptivo y, en otros, un enfoque pre-científico. La parte gráfica ocupa la mitad del área impresa y cumple, en general, una función explicativa respecto al texto escrito, pero la calidad de los mapas es baja. Se ha encontrado en todos los libros un importante número de errores, tanto de carácter informativo como conceptual, y presentan a Aragón como una región rural, atrasada y productora de alimentos y materias primas, lo cual constituye un falso estereotipo.
\end{abstract}

Palabras clave: Aragón, libro de texto, educación primaria, imagen mental, estereotipo.

\begin{abstract}
This paper is aimed at revealing the image of Aragon (Spain) that textbooks of primary education communicate to children. The conclusions we reach are that all textbooks keep to the classical academic pattern, distinguishing ones with a merely descriptive approach from others with a pre-scientific one. Graphics are half the printed area and serves the function of explaining the written text, but the maps are of low quality. All textbooks hold an important number of factual and conceptual errors, and show Aragon like a rural and backward region producing foods and raw materials, which is a wrong stereotype.
\end{abstract}

Key words: Aragon (Spain), textbooks, primary education, mental image, stereotype.

\section{Introducción}

La Ley Orgánica General del Sistema Educativo (LOGSE) establece que la Educación Primaria es el nivel escolar obligatorio para los niños de 6 a 12 años. Ese 
intervalo de edad corresponde de modo aproximado a lo que Piaget denomina la etapa de las operaciones concretas (Piaget e Inhelder, 1981), previa a la adquisición de la plena capacidad de abstracción y del pensamiento hipotético-deductivo. Por ello, los contenidos educativos no pueden organizarse sobre la base de las disciplinas científicas, para cuya práctica dichas capacidades son indispensables, sino sobre la base de áreas que hacen referencia a diferentes formas de comunicación y al conocimiento del entorno, siguiendo un enfoque globalizador que permita abordar los problemas, las situaciones y los acontecimientos dentro de un contexto y en su totalidad. Una de dichas áreas recibe el nombre de "Conocimiento del Medio Natural, Social y Cultural".

Entre los objetivos generales que deben alcanzar los alumnos, según el real decreto 1344/1991, por el que se establece el currículo de la Educación Primaria, figura el siguiente: "Comprender y establecer relaciones entre hechos y fenómenos del entorno natural y social, y contribuir activamente, en lo posible, a la defensa, conservación y mejora del medio ambiente" (Boletîn Oficial del Estado, núm. 220, 1991, p. 30.227). Dicho objetivo se concreta y amplía en los siguientes objetivos generales del área de Conocimiento del Medio: “Analizar algunas manifestaciones de la intervención humana en el medio, valorar críticamente la necesidad y el alcance de las mismas y adoptar un comportamiento en la vida cotidiana acorde con la postura de defensa y recuperación del equilibrio ecológico y de conservación del patrimonio cultural", "identificar los principales elementos del entorno natural, analizando sus características más relevantes, su organización e interacciones y progresando en el dominio de ámbitos espaciales cada vez más complejos", "interpretar, expresar y representar hechos, conceptos y procesos del medio socio-natural mediante diferentes códigos (cartográficos, numéricos, técnicos), e "identificar, plantearse y resolver interrogantes y problemas relacionados con elementos significativos de su entorno, utilizando estrategias, progresivamente más sistemáticas y complejas, de búsqueda, almacenamiento y tratamiento de información, de formulación de conjeturas, de puesta a prueba de las mismas y de exploración de soluciones alternativas" (B.O.E., suplemento del núm. 220, 1991, p. 5).

La lectura de dichos objetivos lleva a la conclusión de que se pretende que todos los españoles adquieran a lo largo de la educación primaria un conocimiento que, sin duda, se puede calificar como geográfico, aun cuando la geografía, en tanto que disciplina científica, no esté presente como tal. Así se desprende de la concepción de "medio" implícita en la formulación de los objetivos, que responde a un enfoque a la vez ecológico y espacial, y del planteamiento metodológico, que exige el dominio de diferentes códigos, entre ellos el cartográfico, así como el de procedimientos de investigación y resolución de problemas.

El progreso en el dominio de ámbitos espaciales cada vez más complejos implica empezar por los más familiares para el alumno, aquéllos en que se desenvuelve su vida cotidiana, para llegar hasta el conjunto del planeta, pasando por su región y su 
país. Teniendo en cuenta que la experiencia directa y personal de los escolares se reduce a ámbitos muy reducidos, el aprendizaje escolar juega un papel fundamental en la construcción de la imagen que cada individuo va formándose de los ámbitos más extensos y complejos, como la región en que vive o España. Los materiales curriculares y, en particular, los libros de texto proporcionan determinada información de cada territorio, estructurada de determinada manera, con lo que contribuyen poderosamente a la construcción de dichas imágenes.

La geografía del comportamiento y de la percepción postula que la conducta humana incide en el medio real, pero se genera a partir de las imágenes mentales que los individuos tienen del mismo. Esta corriente de pensamiento ha hecho una aportación fundamental a la didáctica de la geografía al poner de relieve que sólo a partir del conocimiento de las imágenes mentales que los alumnos tienen de realidades espaciales concretas pueden diseñarse estrategias de enseñanza eficaces para el aprendizaje de conocimientos, destrezas y actitudes sobre el espacio (Marrón Gaite, 1999).

Como señala Sánchez Sánchez (1996), con anterioridad a los años ochenta no era frecuente que los geógrafos tratasen el tema de los recursos didácticos para la enseñanza de la geografía. A partir de esa década la bibliografía se hace más abundante, pero los autores se muestran interesados fundamentalmente por los de carácter no textual: mapas (Valverde Ortega, 1990), fotografías y diapositivas (Long y Roberson, 1979; Sancho Comíns, 1980), cine y vídeo (Zárate et al., 1982-83; Rubio Benito, 1996), trabajo de campo (Sánchez Ogallar, 1996), juegos de simulación (Aranda, 1986; Marrón Gaite, 1990 y 1991), laboratorio (Fidalgo, Galán y González, 1996) o materiales informáticos (Santos Preciado, 1996). Podría decirse que la comunidad geográfica pone especial empeño en mostrar que la enseñanza de la geografía no tiene por qué ser "libresca", sino que hay recursos suficientes para que resulte viva, en contacto con la realidad y abierta a las innovaciones tecnológicas, actitud compartida, sin duda, por el conjunto de los geógrafos actuales y bien arraigada en su tradición docente.

No obstante, el libro de texto sigue desempeñando un papel fundamental en la enseñanza de la geografia: por lo general, los escolares de enseñanza primaria y secundaria tienen prescrito, al comenzar cada curso académico, uno determinado y, más aún, "los proyectos editoriales, una vez elegidos por los profesores, se convierten en el currículo de centron (Sánchez Sánchez, 1996, p. 8). Esto, conviene resaltarlo, no es una peculiaridad española; en el Reino Unido, país en el que la enseñanza de la geografía goza de un merecido prestigio, son muchos los colegios en que el curriculum de geografía está dominado por el uso de un único libro de texto (Lambert y Balderstone, 2000). Superada la época en que era considerado el compendio de todo lo que el estudiante debía aprender, consideración que fue causa de su desprestigio, puede hablarse hoy de una revalorización del libro de texto escolar, que sigue siendo el material curricular básico, aunque no el único. 
Por ello sería conveniente que la comunidad geográfica española mostrase más interés hacia los libros de texto que se usan en la enseñanza primaria y secundaria, valorando su calidad formal, la pertinencia de sus contenidos, desde el punto de vista científico y didáctico, y la imagen del entorno que transmiten a los escolares, aspecto éste en el que se centra el presente trabajo.

\section{Objetivos y metodología}

El objetivo del artículo es desvelar la imagen regional de Aragón que transmiten los libros de texto de educación primaria, mediante el análisis de la información que proporcionan y de la manera en que organizan o estructuran dicha información.

En coherencia con el progreso en el dominio de ámbitos espaciales cada vez más complejos, recogido en los objetivos generales del área de conocimiento del medio, el estudio de las regiones españolas y de España en su conjunto se desarrolla en el último ciclo de educación primaria, que abarca los cursos quinto y sexto, por lo que el trabajo se ha centrado en los libros de texto de dicha área de estos dos cursos terminales.

El análisis se ha circunscrito a los libros utilizados en los colegios de Aragón, que, según el estudio realizado por García Pascual (1997), son los de las editoriales Santillana, Anaya, S.M., Edebé, Vicens-Vives y Edelvives, que se utilizan, respectivamente, en el 32, 28, 18, 9, 7 y 6 por ciento de los colegios aragoneses.

El análisis de los libros se realiza desde un punto de vista geográfico y didáctico; el punto de vista geográfico aporta los criterios fundamentales para desvelar la imagen de la región que transmiten los libros; el punto de vista didáctico aporta los criterios básicos para valorar la calidad y eficacia de dicha transmisión. Para realizar de forma objetiva dicho análisis se elaboró la guía que se reproduce en el cuadro 1, inspirada en los trabajos de Martínez Bonafé (1995) y García Pascual (1997), de los cuales, en consonancia con el objetivo de este artículo, se han tomado en consideración sólo los aspectos relacionados con el contenido de los libros, aun cuando ambos incluyen en sus guías otros aspectos educativos.

Mientras se llevaba a cabo el análisis se comprobó, no sin sorpresa, que los libros contenían un número en absoluto despreciable de errores, lo cual hizo aconsejable hacer una recopilación exhaustiva de ellos y la correspondiente clasificación, para proceder luego a una valoración de su incidencia en la construcción por los escolares de una determinada imagen de Aragón. 
1. ¿Las unidades didácticas dedicadas al estudio de la Comunidad Autónoma se refieren especificamente a Aragón o genéricamente a cualquiera de ellas?

2. Comparando las unidades didácticas dedicadas a la Comunidad Autónoma de Aragón con las dedicadas a España y otros territorios:

2.1. ¿Se aprecia la misma calidad en cuanto a impresión, imágenes y presentación general?

2.2. ¿Se aprecia la misma calidad en cuanto a los contenidos y las actividades propuestas?

3. En las unidades didácticas dedicadas a la Comunidad Autónoma de Aragón:

3.1. ¿Predominan los aspectos culturales, históricos, políticos, geográficos o de otro tipo?

3.2. ¿Existe un enfoque interdisciplinar o globalizador?

3.3. ¿Qué importancia relativa se da a los diferentes aspectos geográficos?

3.4. ¿Los aspectos geográficos se tratan de forma aislada o se relacionan entre sí?

3.5. ¿Qué proporción guardan los siguientes tipos de contenidos educativos: hechos, conceptos, principios, procedimientos y actitudes?

3.6. ¿Qué proporciones guardan los textos y las imágenes, especialmente los mapas?

3.7. ¿Qué función desempeñan las imágenes con respecto al texto: explicativa, motivadora, estética?

Fuente: Elaboración propia, a partir de Martínez Bonafé (1995) y García Pascual (1997)

Cuadro 1. Guía de análisis de los libros de texto del área de Conocimiento del Medio (cursos $5^{\circ}$ y $6^{\circ}$ de Educación Primaria) utilizados en la comunidad autónoma de Aragón

\section{Presencia de Aragón en los libros de texto de Primaria}

Dentro de los libros de texto analizados hay uno que no lleva a cabo un estudio específico de Aragón ni de ninguna otra región. Es el de la editorial Edelvives, en el cual los temas con un enfoque espacial ofrecen información sólo a escala del conjunto de España.

En este libro se intenta paliar la ausencia de referencias regionales recurriendo a dos procedimientos: primero, plantear al alumno en cada tema dedicado a España una serie de actividades relacionadas con la propia comunidad autónoma. Dichas actividades están formuladas en términos genéricos, como en el ejemplo siguiente: "Con ayuda del atlas, infórmate sobre el tipo de suelo que predomina en tu comunidad autónoman. Pero no se aporta información sobre ninguna de ellas, sino que se pide al alumno que la busque él.

Segundo, dedicar una unidad didáctica a las comunidades autónomas. Pero dicha unidad es también genérica, válida para todas, sin aportar información específica sobre ninguna de ellas.

Resulta llamativo que este planteamiento lo adopte la única editorial cuya sede central se encuentra en Aragón, territorio con un elevado nivel de conciencia regio- 
nal. Probablemente la razón del mismo sea económica: incorporar a los libros de texto el estudio de las regiones implica preparar ediciones distintas para cada una de ellas, lo cual encarece los costes. Las otras cinco empresas editoriales, no obstante, han optado por afrontar dicho coste adicional y en sus libros del último ciclo de educación primaria se dedican espacios, más o menos amplios, pero claramente individualizados, al estudio de las comunidades autónomas.

La editorial Edebé, dentro de este grupo, ha adoptado un planteamiento distinto al de las demás. El estudio de Aragón se lleva a cabo en el libro de quinto curso, que es, por tanto, el único que requiere ediciones diferenciadas por regiones. En este libro los temas que siguen un enfoque espacial están dedicados a España, pero en cada aspecto concreto referido al conjunto del país se introduce información relativa a Aragón. En definitiva, el estudio de la comunidad autónoma no se plantea con carácter monográfico, sino en forma de apéndice o anexo al estudio de España.

Las otras cuatro editoriales, Anaya, Santillana, SM y Vicens Vives, han optado por llevar a cabo un estudio individualizado de cada comunidad autónoma en el libro de quinto curso, que es, igual que en el caso anterior, el único que requiere ediciones diferenciadas, dedicando el de sexto al estudio de España. Estas editoriales, por tanto, adoptan para el último ciclo de primaria un diseño curricular en círculos concéntricos, desde el punto de vista espacial, empezando por el espacio más pequeño y próximo, la región, de la cual realizan un estudio monográfico, para terminar con el más extenso y complejo, España.

Dentro de este grupo la editorial Vicens Vives ha hecho un esfuerzo mayor que las demás, pues en el libro de sexto curso hay un conjunto de temas dedicados a historia de España, en cada uno de los cuales se incluyen informaciones específicas relacionadas con Aragón, lo cual indica que se han preparado ediciones diferenciadas también de este libro.

El análisis que sigue a partir de ahora, en consecuencia, se limita a las cinco editoriales que tratan específicamente de Aragón, no sin antes señalar que el 6 por ciento de los colegios de la comunidad autónoma prescriben a sus alumnos un libro de texto que no ofrece un estudio específico de la misma (el de editorial Edelvives). Pero esto no quiere decir que Aragón no se estudie en dichos colegios; los maestros, como indicaron en las entrevistas mantenidas con ellos, organizan el estudio de la región recurriendo a dos procedimientos: primero, hacer referencias a Aragón cuando tratan cuestiones generales de conocimiento del medio y, segundo, mediante salidas de trabajo, con las correspondientes visitas y estancias.

En los libros de las cinco editoriales que tratan específicamente de Aragón el nombre de la región es claramente visible en la portada, incluso en el de sexto que, excepto en el caso de Vicens Vives, no contiene referencias individualizadas a las comunidades autónomas. En ninguno de ellos se ha apreciado una calidad inferior 
en la parte dedicada a Aragón que en la parte dedicada al conjunto de España, por lo que respecta a la presentación general, ni a la impresión, las imágenes, los contenidos o las actividades. En este sentido, las editoriales han afrontado con seriedad el reto de preparar ediciones diferenciadas por regiones, sin recurrir al fácil expediente de compensar el coste adicional con una rebaja de la calidad.

\section{El enfoque regional en los libro de texto de Primaria}

En todos los casos la comunidad autónoma es el punto de partida. Es decir, ninguno de los libros analizados se plantea qué es una región, qué tipos de regiones pueden diferenciarse en la superficie de la tierra, cuál es el resultado de aplicar al caso español unos u otros criterios de regionalización y cómo encaja Aragón en ese esquema; la región es un hecho, un dato previo, cuya existencia y delimitación se establece en los textos legales correspondientes, la Constitución y el Estatuto de Autonomía. Este planteamiento está muy extendido en todos los campos científicos: "Definir regiones con precisión representa tal pesadilla que la mayoría de los economistas regionales prefiere eludir la tarea y muestra su alivio cuando, debido a consideraciones de tipo político o porque no se dispone de datos referidos a otras unidades espaciales, se les obliga a trabajar con regiones administrativas" (Richardson, 1986, p.13). Lo mismo podría decirse de los geógrafos, como parece indicar la reciente obra de geografía regional de España dirigida por Garcia Alvarado y Sotelo Navalpotro (1999), que está organizada por comunidades autónomas.

Sólo la editorial Edebé se aparta un poco de esta tónica. En el libro de quinto, como ya se ha indicado, se hace un estudio general de España con referencias a Aragón, mientras que en el de sexto se incluye un bloque temático, denominado “España: paisajes e historia”, el cual dedica un tema a realizar una breve introducción a la historia de España y cuatro a un estudio regional del país. En él se diferencian cuatro regiones, a las que se denomina: septentrional, oriental, interior y meridional; se trata, como se ve, de una regionalización realizada a muy grandes rasgos, muy simplificadora. Para llevarla a cabo, como sugiere el título del bloque temático y confirma su lectura, se ha seguido un enfoque paisajistico, pero en su acepción más tradicional, centrado en los aspectos visibles del terreno.

Adoptada, por tanto, la división político-administrativa actualmente vigente en España, la región aragonesa se ajusta a su delimitación oficial en todos los libros de texto analizados. Procede ahora determinar el enfoque con el que se lleva a cabo su estudio.

Todos los libros coinciden en lo esencial a este respecto, pues siguen el esquema de la geografía académica clásica, el que normalmente se conoce como "sistema de archivadores", ampliado para dar cabida a la historia y la política. Se inicia el estudio 
con la geografía física, se continúa con la población y el poblamiento, luego con la geografía económica y se completa con la historia y las instituciones de gobierno. En el bloque de geografía física se estudian el relieve, el clima, la vegetación y los ríos; el de geografía económica aparece dividido en los tres sectores económicos clásicos; en el de historia se incluyen las etapas o edades históricas, el patrimonio artístico y las tradiciones. Todas las editoriales utilizan este esquema para organizar el estudio de Aragón y de España.

Partiendo de esa coincidencia esencial, se dan algunas diferencias entre unos y otros libros. Quizá la más llamativa sea la de editorial Santillana, que empieza por la población y las instituciones, siguiendo por lo demás el orden antes indicado. Otra diferencia consiste en que algunas editoriales organizan los grandes bloques antes señalados de forma unitaria, mientras que otras presentan los distintos elementos de cada bloque en temas independientes; pero esta diferencia no es tan importante en la práctica porque las que optan por lo primero presentan los elementos de cada bloque en forma de apartados claramente individualizados dentro de la unidad didáctica correspondiente.

La historia y las instituciones, dentro del esquema general que siguen los libros, ocupan entre la cuarta y la sexta parte del total, correspondiendo el resto a los contenidos de carácter geográfico. El mayor peso de éstos encuentra su justificación en las aportaciones de la psicología del aprendizaje, según las cuales el espacio y el tiempo son nociones que no se conocen de un modo intuitivo, sino que requieren una verdadera construcción psicológica; en el caso del tiempo ésta se retrasa en muchos aspectos clave hasta la adolescencia (Carretero y Pozo, 1987), mientras que hacia los nueve años se dominan ya bastante bien los sistemas de referencia espacial (Ochaíta, 1983). Parece lógico, por tanto, centrar el conocimiento del medio preferentemente en sus aspectos espaciales $o$, si se prefiere, geográficos y plantear los temporales o históricos a modo de simple introducción. Análogamente, parece razonable plantear de manera meramente introductoria el conocimiento de las instituciones regionales, pues los escolares de primaria, aún en la fase de las operaciones concretas, conciben el gobierno de la comunidad como el mando de unas personas individuales, y no como un sistema de instituciones políticas.

Entrando ahora en la importancia relativa de cada uno de los "archivadores" en que se presenta el estudio geográfico, las diferencias entre las editoriales tampoco son demasiado marcadas: Santillana y Vicens Vives dedican la mitad de las unidades didácticas a la geografía física y la otra mitad a la geografía humana. Las demás dan mayor importancia a esta segunda: el 56 por ciento SM, el 60 Edebé y el 66 Anaya.

Por lo que respecta al contenido de cada "archivador", en el de geografía física se da en todos los libros un tratamiento aproximadamente igual, tanto en la extensión como en la forma de presentación general, al relieve y al clima, lo cual parece razo- 
nable por la similar importancia que tienen ambos elementos en la configuración de los paisajes y en el control de los otros elementos del medio natural, como los ríos y la vegetación, a los que, en general, se da menos relevancia. En el "archivador" de geografía económica reciben un tratamiento paritario los tres sectores clásicos, lo cual significa, si se atiende a su importancia económica, sobrestimar el sector agrario y minusvalorar el terciario, aunque desde el punto de vista paisajístico está claro el mayor interés de aquél.

En resumen, los libros de texto de primaria siguen el sistema de archivadores" tanto para el estudio de las comunidades autónomas españolas como para el de España, aplicando rígidamente el mismo esquema de análisis a todos los territorios, al margen de su tamaño y características. En definitiva, asumen ese planteamiento académico clásico al que Lacoste (1977) denominó críticamente "la geografía de los profesores".

El principal inconveniente de este planteamiento es que presenta los diversos componentes naturales y sociales del entorno como elementos aislados, lo cual dificulta la construcción de una imagen global e integrada de la región y, en general, del medio. Algunas editoriales, no todas, establecen relaciones significativas entre dichos elementos, lo cual favorece su integración, pero no lo hacen de forma sistemática, sino ocasional. El mayor esfuerzo, en este sentido, corresponde a la editorial Vicens Vives, que desarrolla una unidad didáctica sobre la conservación del medio ambiente, que, no obstante, se limita a las situaciones extremas: los espacios naturales protegidos, concretamente el parque nacional de Ordesa, en los que los elementos sociales están casi completamente ausentes, y las grandes ciudades, concretamente Zaragoza, que son entornos artificiales creados por la sociedad.

La falta de integración de los elementos, por otra parte, dificulta que los escolares de educación primaria conciban Aragón como una región funcional, cuyo lugar central es Zaragoza, no ya con toda la complejidad que eso lleva consigo, que escapa a la capacidad de comprensión propia de esas edades, pero ni siquiera con la simplicidad de una noción preliminar que vaya más allá de saber que Zaragoza es la capital de la comunidad autónoma.

Si no se hace un estudio integrado de los elementos geográficos de la región, tampoco se hace un planteamiento interdisciplinar que permita integrar los elementos geográficos, históricos y de otras ciencias. Un ejemplo bastante representativo de esto lo ofrece el desigual tratamiento que la editorial Edebé da a dos temas incluidos en el bloque de los elementos del paisaje natural: en el dedicado al clima y los ríos se estudian los de España, con referencias a Aragón, mientras que en el dedicado a los ecosistemas se habla de ellos en abstracto, siguiendo la óptica sistemática de las ciencias naturales, sin incluir ninguna referencia territorial a España ni a Aragón, cuando ambos territorios ofrecen excelentes ejemplos de ecosistemas. 


\section{El estudio de Aragón y los tipos de contenidos educativos}

El real decreto 1344/1991, por el que se establece el currículo de la Educación Primaria, divide los contenidos educativos en tres tipos: conceptuales, procedimentales y actitudinales. Los primeros se identifican con los contenidos tradicionalmente prescritos en los planes educativos y hacen referencia a la información - los conocimientos que deben asimilar los alumnos. Los segundos se refieren a un saber cómo, un saber operativo que trata de contenidos que permiten adquirir otros conocimientos. Los terceros tienen que ver con las pautas de comportamiento que se deben adquirir. Todos ellos han de estar presentes, sin que ninguno quede en segundo plano, a lo largo de todo el proceso educativo y en todas las áreas.

El citado decreto, por otra parte, indica que el proceso de enseñanza debe organizarse de manera que los alumnos realicen un aprendizaje significativo. Esto quiere decir, por lo que respecta a los contenidos conceptuales, que los conocimientos que debe adquirir el alumno no pueden reducirse a datos o hechos aislados, lo cual exige un aprendizaje puramente memorista, sino que deben ser organizados mediante conceptos y principios para construir estructuras cognitivas progresivamente más complejas. Respecto a los procedimientos, no basta con que el alumno sea capaz de ejecutar mecánicamente determinadas tareas, sino que debe aprender cuál es la secuencia de actividades adecuada en función de la meta a alcanzar. Por lo que respecta a las actitudes, no se trata sólo de que adopte tal o cual conducta correcta, sino de que haga suyo un determinado sistema de valores y sepa organizar en función de él sus pautas de comportamiento.

Este apartado va dedicado a valorar hasta qué punto el estudio de Aragón, tal como se presenta en los libros de texto de educación primaria, responde a la pluralidad de contenidos educativos establecida en las disposiciones legales vigentes y si facilita o dificulta el aprendizaje significativo de los mismos por parte de los alumnos.

En este aspecto es donde se aprecian más diferencias entre los libros de texto analizados, hasta el punto de que puede hablarse de dos modelos distintos a la hora de plantear el estudio de Aragón:

En el primero los contenidos conceptuales consisten fundamental o exclusivamente en hechos o datos, es decir, en informaciones puntuales, como nombres de sierras y ríos, relación de producciones agrarias o industriales o número de habitantes; dichos datos no aparecen estructurados en conceptos y principios. Los contenidos procedimentales se reducen a la ejecución mecánica, como reproducir mapas incluidos en el libro. Finalmente, los contenidos actitudinales se presentan desconectados del resto y se limitan a "inculcar" a los alumnos una actitud de respeto al medio ambiente y al patrimonio cultural. 
En el segundo modelo las informaciones puntuales aparecen asociadas a conceptos y principios. Los procedimientos aparecen integrados en el conjunto de las unidades didácticas; por ejemplo, la realización de un climograma, a partir de datos de una estación meteorológica aragonesa, permite que los alumnos aprendan un procedimiento general de tratamiento de la información a la vez que comprenden las características climáticas de la zona de estudio. Las actitudes, finalmente, se trabajan a la vez que el resto de los contenidos, tratando de suscitar en los alumnos la adhesión emocional a determinados valores.

Estos dos modelos han sido definidos de forma estilizada, por lo que los libros analizados no responden exactamente a ninguno de ellos, aunque se aproximan más a uno que a otro. Por otra parte, debe tenerse en cuenta que lo que aquí se está valorando es únicamente la forma de plantear el estudio de Aragón, sin que dicha valoración deba extrapolarse mecánicamente a todo el contenido de los libros.

Se aproxima mucho al primer modelo el libro de la editorial Santillana, del que podría afirmarse incluso que tiene miedo a utilizar conceptos, como ilustra este ejemplo: en el apartado dedicado a la población aragonesa se incluye un mapa en el que se representan áreas "muy pobladas", "medianamente pobladas" y "escasamente pobladas", sin mayor precisión. Si se hubiera introducido el concepto de "densidad de población", con todas las cauciones necesarias atendiendo a la edad de los alumnos, éstos dispondrían de un instrumento de trabajo intelectual adecuado para trabajar con todos los casos posibles, mientras que la presentación realizada en el libro no permite ir más allá del caso de Aragón, que, por otra parte, queda estudiado de una manera muy imprecisa. Cabe señalar, en relación con esto mismo, que una de las actividades que más frecuentemente se propone al alumno es completar "mapas conceptuales", que se le facilitan ya medio elaborados, pero lo cierto es que para completar la mayor parte de ellos el alumno no tiene que introducir conceptos, sino datos o hechos, lo que no es sino una adulteración de lo que en realidad es un mapa conceptual.

Esta editorial aparentemente presta mucha atención a los procedimientos, pues en todas las unidades didácticas se incluye un apartado titulado "saber hacer"; pero la mayor parte de las actividades propuestas en él consisten en reproducir los mapas que el propio libro incluye en páginas anteriores. Otro apartado fijo en todas las unidades se titula "informe", que consiste en que el alumno complete un texto del que se han borrado algunas palabras, siendo la mayor parte de ellas datos que el alumno encuentra con toda facilidad tras una lectura rápida y mecánica de las páginas precedentes; tal como está planteado se trata también de una adulteración de lo que se entiende habitualmente por informe. Finalmente, en todas las unidades se incluye también un apartado titulado "actitudes", que consiste en un texto sobre algún aspecto relacionado con el contenido de la unidad (por ejemplo, sobre los ibones pirenaicos en la unidad del relieve), seguido de algunas preguntas a partir de las cuales se pretende propiciar actitudes de respecto al medio ambiente o al patrimonio. 
Las editoriales cuyos libros se aproximan más al segundo modelo son SM y Anaya. En ambos casos cada unidad didáctica contiene conceptos y principios relevantes para procesar las informaciones puntuales que se facilitan sobre Aragón; asimismo, los procedimientos que se trabajan en cada unidad exigen una serie de acciones por parte de los alumnos, es decir, no son mecánicos, y además están relacionados con Aragón. Por ejemplo, el libro de SM inicia la unidad dedicada al relieve regional con un apartado en el que explica qué es el relieve y cuáles son las principales formas de relieve (montaña, llanura), pasando después a explicar cómo se representa en los mapas, para lo cual se toma como ejemplo el mapa de Aragón; a partir de ahí, una vez definidos los conceptos fundamentales y presentada la herramienta de trabajo precisa, se pasa a describir el relieve de la región, aportando la información correspondiente. De esta manera el alumno no tiene que procesar los datos de forma puramente memorista, sino que dispone de los instrumentos conceptuales y procedimentales adecuados para realizar un aprendizaje significativo.

Otro ejemplo se puede extraer del libro de editorial Anaya, que inicia el tema dedicado a la población explicando cómo se hace un censo y proponiendo a los alumnos la confección de uno muy simple a partir de ellos mismos y sus familias; con ese punto de partida es más fácil entender la estructura y demás características de la población aragonesa, a lo que van dedicados los restantes apartados del tema.

No obstante lo anterior, ninguno de los dos libros es el modelo ideal, pudiendo señalarse algunas características que los alejan del mismo. En primer lugar, la mayoría de las actividades están planteadas de una manera muy dirigida y van encaminadas al dominio de técnicas concretas; rara vez plantean problemas de una cierta complejidad que obliguen al alumno a desarrollar el proceso completo, desde la formulación de una conjetura hasta la verificación de la misma, pasando por la búsqueda y procesamiento de la información, actividades todas ellas mencionadas explícitamente en el decreto que establece el currículo de educación primaria. En segundo lugar, algunas actividades son puramente mecánicas (SM propone calcar un mapa de los ríos de Aragón, sin más) y otras están desconectadas del resto de la unidad, de manera que no parecen tener otro objetivo que ellas mismas (Anaya enseña a hacer un perfil topográfico, pero no se utiliza luego para nada ni se indica o sugiere para qué puede ser útil). En tercer lugar, los contenidos actitudinales tienen un tratamiento mucho más pobre, tanto en términos cuantitativos como cualitativos.

Los libros de las editoriales Edebé y Vicens Vives quedan más alejados de los dos modelos, en la forma estilizada en que se han descrito, aunque se aproximan más al primero que al segundo.

En resumen, los libros de texto de educación primaria abordan el estudio de Aragón de manera diferente: unos se acomodan a un planteamiento fundamentalmente descriptivo, en el que prima la simple acumulación de datos, mientras que otros se aproximan a un planteamiento pre-científico (en la etapa de las operaciones concretas no 
puede ser plenamente científico, sino preparatorio), en el que junto a los datos se incluyen las herramientas conceptuales y procedimentales necesarias para su procesamiento. Mientras que el primero recuerda el sistema tradicional de enseñanza, fuertemente memorista, el segundo favorece el aprendizaje significativo de los alumnos.

\section{Texto e imagen en el estudio de Aragón}

A diferencia de los que utilizaron generaciones pasadas, los libros de texto actuales, tanto en educación primaria como en secundaria, contienen una gran cantidad de imágenes y elementos gráficos que acompañan al texto, el cual, por su parte, se presenta con una notable diversidad de tipos, tintas y composiciones. Se puede afirmar, de entrada, que los libros de ahora tienen un potencial educativo superior a los de antes, pues la combinación de palabra e imagen facilita la capacidad de comprensión y favorece el aprendizaje significativo. Pero la evolución de los libros de texto es la misma que se ha producido en otras clases de libros, como los de divulgación científica, por ejemplo; las posibilidades tipográficas se han incrementado espectacularmente en las últimas décadas, gracias a los avances en las técnicas de tratamiento de la información, y eso repercute en todo tipo de material impreso.

La cuestión que interesa dilucidar aquí es si en los libros de texto de educación primaria que abordan el estudio de Aragón se han aprovechado eficazmente, desde el punto de vista didáctico, los recursos tipográficos ahora disponibles.

En todos los libros analizados las imágenes que acompañan al texto son abundantes y variadas, incluyendo fotografías, dibujos, gráficos de diferentes clases y mapas; a ellas corresponde en torno a la mitad del área impresa. La integración entre texto e imagen es, en general, buena: el texto remite sistemáticamente a las imágenes que lo acompañan y éstas, también en general, tienen una función explicativa con respecto al texto, contribuyendo a ilustrarlo, a aclararlo y, en definitiva, a comprenderlo mejor. Además de esta función explicativa, algunas imágenes son el soporte o punto de partida de determinadas actividades, puramente mecánicas en algunos casos o más creativas en otros, como ya se ha indicado.

No obstante, en todos los libros hay una cierta proporción de imágenes que se presentan desconectadas del conjunto, sin que parezcan tener otra función que la meramente estética o incluso la de simple relleno. Esto es frecuente en el caso de las fotografías, aunque algunas cumplen muy bien las funciones explicativa o procedimental antes señaladas.

De cara a la adquisición del conocimiento geográfico, los mapas juegan un papel de especial relevancia. Los libros de texto analizados coinciden en la inclusión de un 
importante número de mapas de Aragón, tanto topográficos como temáticos. Los primeros representan los límites administrativos regionales y provinciales, los ríos, las principales localidades y vías de comunicación y el relieve, éste por medio de tintas altimétricas. Los segundos representan ciertas características climáticas, demográficas, económicas e históricas.

Pero si la cantidad de mapas es alta, su calidad es bastante baja, en términos generales. Los defectos encontrados con más frecuencia son los siguientes:

En la mayor parte de los mapas no se incluye la escala, ni numérica ni gráfica. La inclusión de la misma es exigencia imprescindible desde el punto de vista geográfico, pero también desde el punto de vista curricular, pues la escala es uno de los contenidos recogidos explícitamente en el decreto que establece el currículo de primaria. Se da la contradicción de que las editoriales, en cumplimiento del citado decreto, incluyen un apartado en el que se define lo que es la escala y se plantean ejercicios para asegurar el dominio práctico de la misma, pero luego no consta la escala de los mapas, con lo que, lógicamente, se transmite al alumno la idea de que no tiene importancia.

Prácticamente en la totalidad de los mapas Aragón se representa completamente aislado del resto de España, como si se tratara de una pieza de rompecabezas o un recortable. Esto hace difícil situar Aragón en el contexto español y comprender que una gran parte de los elementos cartografiados tienen continuidad más allá de las fronteras regionales, tanto las unidades de relieve o los ríos como las vías de comunicación.

Algunos libros incurren en contradicciones ingenuas a este respecto, como muestra el siguiente ejemplo, tomado del de la editorial Anaya: una actividad consiste en rellenar un cuadro impreso relativo a los principales ríos de Aragón, de cada uno de los cuales debe anotar el alumno, fijándose en los mapas del propio libro, el nacimiento, la desembocadura y los principales embalses; los mapas presentan Aragón de la forma aislada que se ha indicado y dos de los ríos incluidos en el cuadro son el Ebro y el Mijares, cuyas desembocaduras, evidentemente, no aparecen en los mapas, como tampoco el nacimiento y algunos de los principales embalses del Ebro.

Sería más lógico incluir en la representación los territorios limítrofes con Aragón hasta donde fuera necesario en cada caso; en el ejemplo señalado habría sido conveniente incluir la totalidad de las cuencas del Ebro y Mijares, habiendo recursos tipográficos suficientes para que Aragón apareciese en dichos mapas resaltado y claramente diferenciado de otros territorios.

La "legibilidad" de muchos mapas se ve dificultada por la inclusión de un número excesivo de categorías y, sobre todo en los mapas de geografía humana, por un uso masivo de símbolos puntuales e icónicos, cuya identificación con la realidad representada es muy sencilla, pero cuya localización e importancia cuantitativa resultan muy imprecisas. Valga como ejemplo que casi todos los libros coinciden en repre- 
sentar las producciones agrarias mediante espigas, racimos de uvas, aceitunas y símbolos de este tipo, que aparecen dispersos por los mapas; en muchos casos la localización de los símbolos es errónea, y en casi todos poco precisa. El presentar mapas de utilización de suelo simplificados habría resultado más exacto y la dificultad adicional de comprensión quedaría compensada con la adquisición por parte de los alumnos de una mayor destreza a la hora de dominar el lenguaje cartográfico.

\section{Errores y estereotipos en el estudio de Aragón}

Sin duda uno de los aspectos más criticables de los libros de texto de educación primaria es la existencia de un número de errores nada desdeñable, que se da en todos los analizados, si bien debe tenerse en cuenta que esta afirmación se refiere exclusivamente a la parte de los libros dedicada al estudio de Aragón, sin que deba extrapolarse a su totalidad.

En primer lugar, hay que señalar un número importante de errores en los datos que se facilitan. En unos casos se trata de datos desfasados, como se ve en los siguientes ejemplos: en el libro de editorial Edebé se cita entre las producciones primarias aragonesas la remolacha azucarera, cultivo abandonado hace décadas; los de Edebé y Anaya citan la producción de hierro de las minas de Ojos Negros, cerradas en 1986; en el de Santillana se atribuye a los yacimientos del Serrablo las tres cuartas partes de la producción de gas natural español, cuando en realidad fueron abandonados, por agotamiento, en 1990; editorial SM dice que el ganado ovino suele practicar la trashumancia, que hoy es una práctica residual.

En otros casos se trata de valoraciones erróneas: Edebé cita como las sierras más importantes del Sistema Ibérico en Aragón las de Albarracín y Javalambre, ignorando que en la sierra del Moncayo se encuentra la altitud máxima de la cordillera; SM dice que uno de cada tres aragoneses vive en una localidad urbana, proporción muy inferior a la real.

En otros casos se trata de omisiones inexplicables: SM y Vicens Vives olvidan mencionar entre las industrias localizadas en la región la fábrica de automóviles de Opel España; al citar las denominaciones de origen vinícolas Vicens Vives omite la de Calatayud.

También se pueden mencionar errores en los nombres: Vicens Vives habla de la denominación de origen vinícola de Barbastro, en vez de Somontano.

Finalmente, hay también errores de localización: Vicens Vives localiza la laguna de Gallocanta en la Depresión Central de Aragón, o sea en la del Ebro; Santillana dice 
que el tío Gállego forma el embalse de la Sotonera, que Calatayud se encuentra en la cuenca baja del Jalón o que Tarazona y Borja están en la ribera del Ebro.

Este tipo de error quizá sea el menos grave, pues un dato erróneo o una información puntual equivocada resultan fáciles de subsanar por parte del maestro y, en consecuencia, no debe dárseles demasiada importancia. Pero, en todo caso, reflejan un descuido o, si se prefiere, una falta de control de calidad difícilmente justificable.

Más graves son los errores conceptuales, puesto que los conceptos, en tanto que abstracciones de acontecimientos, situaciones, objetos o propiedades, permiten clasificar y organizar las propias experiencias, por lo que son herramientas básicas para la construcción del conocimiento. Aunque en los libros analizados no se han encontrado definiciones mal formuladas, sî hay expresiones que llevan implícita una definición incorrecta de términos. Véanse los siguientes ejemplos: en el de editorial Edebé al establecer los límites regionales se indican las comunidades autónomas limítrofes de Aragón (como es lógico, puesto que es una comunidad autónoma), excepto por el norte, donde se dice que limita con los Pirineos; esto dificulta asimilar el concepto de "límite" y "limítrofe": ¿cómo puede ser limítrofe un espacio que está a la vez dentro y fuera de la región? En el de editorial Vicens Vives se escribe textualmente "en el monte bajo, hasta los 400 metros abundan las encinas", de donde se infiere que la expresión "monte bajo" tiene que ver con la altura del terreno, cuando en realidad sirve para denominar un tipo de formación vegetal.

Dentro de los errores conceptuales se incluyen también los que se refieren a jerarquías mal estructuradas: dado que unos conceptos van incluidos en otros de orden superior, los libros de texto deben facilitar la tarea de establecer correctamente las relaciones jerárquicas que eso conlleva. Abundan también los errores de este tipo: la editorial Vicens Vives titula uno de sus apartados "La Depresión central y los somontanos", con lo que da a entender que se trata de dos unidades de relieve diferentes, pero al desarrollar dicho apartado se explica que en la Depresión central se pueden distinguir tres unidades, una de las cuales es los somontanos. En el bloque de geografía económica del mismo libro se distingue, por una parte, "el sector servicios"y, por otra, "el comercio y los transportes". La editorial Edebé estudia la minería en dos temas distintos, los dedicados a los sectores primario y secundario.

Otra clase de errores, esta vez de carácter didáctico, consiste en escoger variables inadecuadas para representar ciertos fenómenos. Véanse estos dos ejemplos: editorial Santillana informa sobre las principales producciones agrícolas de Aragón mediante un diagrama de barras, en el que se representan las toneladas producidas; los datos son correctos y el diagrama está bien hecho, pero con este sistema se equiparan una tonelada de alfalfa con una de melocotones, aun cuando su valor económico es completamente diferente. El mismo error se aprecia en el libro de editorial Anaya, que mediante un diagrama de barras informa de las principales producciones ganaderas 
de Aragón, utilizando como variable el número de cabezas, con lo que se le da la misma importancia a un pollo que a un cerdo.

Estos errores son más graves de lo que parece a primera vista porque contribuyen a crear una imagen distorsionada de la región; los usuarios de los libros citados pensarán que en Aragón tiene mucha más importancia el cultivo de alfalfa que el de melocotones y la cría de pollos que la de cerdos.

En resumen, todos los libros analizados, sin excepción, contienen una cantidad y variedad de errores difícilmente justificable, más aún si se tiene en cuenta que los aquí señalados no constituyen una relación exhaustiva, sino una muestra amplia. En numerosos campos de la actividad humana hay una larga tradición de controles de calidad, siendo cada vez más exigentes las normas a este respecto, hasta el punto de que en numerosos procesos productivos se está hablando ya de "error cero", no como meta a la que tender a largo plazo, sino como objetivo concreto a alcanzar ya. Sin duda alguna, en la producción de libros de texto de primaria no existen esos niveles de exigencia, siendo los controles de calidad inexistentes o poco eficaces.

Pero el análisis de bastantes de los errores detectados acaba llevando a la convicción de que no sólo fallan los controles de calidad, sino que además los autores y revisores de los libros actúan bajo la influencia de ciertos estereotipos, de manera que no son conscientes de que se están equivocando, sino todo lo contrario, probablemente estén convencidos de que su trabajo es correcto y de que transmiten una imagen bien enfocada de Aragón. Aunque apreciable en todos los casos, el estereotipo resulta más evidente en el caso de dos editoriales, SM y Vicens Vives, a las que antes se ha citado por haber coincidido en el error de omitir a Opel España entre las industrias establecidas en la región.

En la unidad 19 del libro de $5^{\circ}$ de Vicens Vives, titulada "Los recursos económicos de Aragón", aparece escrito textualmente lo que sigue: "Nuestra Comunidad importa pescado, arroz o electrodomésticos y exporta sus productos, energía eléctrica, cereales, fruta, carne, etc. a las Comunidades limítrofes". Aragón es, a la luz de este texto, una región productora y exportadora de alimentos y energía, es decir, de productos primarios. El mismo libro, en la unidad 18, titulada “La población de Aragón", ejemplifica los movimientos migratorios regionales con datos de 1960 a 1980 y, para remachar la imagen de región marcadamente emigratoria que de ello se desprende, recoge la contabilidad demográfica sólo del año 1970. Parece claro que los autores y correctores de la editorial Vicens Vives tienen una imagen estereotipada de Aragón como región de emigrantes y económicamente especializada en la producción de alimentos y materias primas y que así lo transmiten abiertamente, buscando datos que confirmen esa imagen, aunque sean anticuados, e ignorando (hay que suponer que no maliciosamente, sino por no haber caído en la cuenta) que Aragón posee una potente industria de automóviles y electrodomésticos, entre otras, cuyos productos se exportan en cantidades masivas, no sólo a las regiones limítrofes, sino prácticamente a todo el mundo. 
La editorial SM ha trabajado con el mismo estereotipo, como se desprende de las siguientes citas textuales: la industria aragonesa se reduce a "muchas pequeñas industrias derivadas de la agricultura y la ganadería"; de la ganadería se dice que "en nuestra comunidad predomina el ganado ovino, que suele practicar la trashumancian; de la población se dice que "uno de cada tres aragoneses vive en una localidad urbanan. Como en el caso anterior, a los autores y revisores de SM les ha cegado el estereotipo de un Aragón rural, de ganadería tradicional y modesta industria de transformación de productos agrarios, y no han caído en la cuenta del enorme peso demográfico de Zaragoza ni de que la región ha experimentado un importante proceso de modernización agropecuaria e industrial.

En definitiva, como muestran los ejemplos señalados, los libros de texto de educación primaria transmiten una imagen de Aragón ajustada al estereotipo de región de emigrantes, rural y de economía agraria, estereotipo muy extendido todavía en el conjunto del país e incluso en la propia región.

Pero, precisamente, lo que deben hacer los libros de texto no es consolidar o fosilizar falsos estereotipos, sino todo lo contrario, procurar "echarlos abajo". Como se sabe desde los trabajos pioneros de Piaget, la mente infantil no es una hoja en blanco, sino una estructura cognitiva organizada, de manera que los nuevos conocimientos sólo se podrán integrar en dicha estructura si encajan en ella, si resultan compatibles con ella. Por eso, al fijar en el alumno de primaria un estereotipo regional falso, además de enmascarar la realidad, se está bloqueando la posibilidad de que dicho alumno construya en el futuro una imagen correcta de la región; para ello será menester desmontar dicha estructura, dicho estereotipo, y sólo entonces se podrá construir una imagen nueva a partir de conocimientos correctos.

\section{Conclusiones}

Del análisis realizado se concluye que las editoriales de libros de texto de educación primaria se han adaptado a las nuevas prescripciones curriculares mediante la preparación de ediciones diferentes para las comunidades autónomas españolas, diferencias que afectan sólo a los libros del último ciclo y no en su totalidad, sino en una parte; no obstante, esta línea no la han seguido todas las empresas, pues algunas siguen lanzando al mercado una sola edición de alcance nacional, que no incluye información específica sobre ninguna de las comunidades autónomas españolas. Las editoriales que han optado por preparar ediciones regionales lo han hecho manteniendo los niveles de calidad del resto de su producción.

El estudio regional que llevan a cabo los libros de texto se acomoda estrictamente a los límites político-administrativos, siguiendo un enfoque fundamentalmente geo- 
gráfico, que se completa con algunos contenidos de carácter histórico y político-institucional; éstos comprenden entre la cuarta y la sexta parte, según editoriales, del espacio dedicado a Aragón.

El enfoque geográfico que se sigue en todos los libros es el académico tradicional, el llamado "sistema de archivadores", objeto de críticas dentro del campo científico de la geografía, críticas que han puesto en evidencia, por una parte, la rigidez de su planteamiento, pues se aplica el mismo esquema de análisis a todas las regiones, y, por otra parte, la presentación de la realidad regional en forma de planos separados, lo cual obstaculiza una visión global e integrada del espacio.

A esa visión fragmentada que dan todos los libros se añade, en el caso de algunos, una presentación puramente descriptiva de la región, centrada fundamental o exclusivamente en datos concretos, con lo cual se apela únicamente a la memoria del alumno, pretendiendo que almacene una información puntual, que olvidará tarde o temprano.

No obstante, en este aspecto hay diferencias sensibles entre unas y otras editoriales, pues algunas han hecho un esfuerzo serio para que las informaciones puntuales aparezcan asociadas a conceptos, principios y procedimientos, con lo cual se facilita su procesamiento para la construcción de un aprendizaje significativo.

En todos los libros el texto escrito va acompañado de una notable variedad y riqueza de imágenes, existiendo una buena integración entre ambas partes, aunque no son pocas las excepciones a esta afirmación general. No obstante, la calidad de algunas imágenes deja bastante que desear. Los mapas, en concreto, suelen aparecer sin escala, presentan a la región aislada de su contexto espacial y plantean problemas serios de legibilidad, por exceso de categorías y por uso inadecuado de símbolos.

Se han detectado numerosos errores en todos los libros de texto, sin excepción, errores que van desde la aportación de datos erróneos, anticuados e incompletos, hasta el uso de expresiones que inducen a error conceptual.

Finalmente, los libros transmiten una imagen estereotipada de Aragón, que aparece en todos los casos, aunque en unos se percibe con más claridad que en otros, como una región atrasada, rural y productora de materias primas, de la que emigra la población.

En resumen, los libros de texto más utilizados en el nivel de educación primaria en Aragón presentan una imagen fragmentada y estereotipada de la región, por lo que no son los instrumentos idóneos para que los escolares aragoneses de dicho nivel educativo construyan una imagen ajustada de su propia tierra. 


\section{Bibliografía}

Aranda Hernando, A.M. (1986): Juego de planificación urbana. En Actas del primer encuentro de profesores de geografia de escuelas universitarias de magisterio. Barcelona, Publicacions i Edicions de la Universitat de Barcelona, pp. 169177.

Carretero, M. y Pozo, J.I. (1987): Desarrollo intelectual y enseñanza de la historia. En La geografia y la bistoria dentro de las ciencias sociales: hacia un curriculum integrado. Madrid, Ministerio de Educación y Ciencia, pp. 11-29.

Fidalgo Hijano, C., Galán Gallego, E. y González Martín, J.A. (1996): El laboratorio y el gabinete como recurso docente: el uso de las técnicas experimentales en geografía física. En Moreno Jiménez, A. y Marrón Gaite, M.J., eds.: Enseñar geografia. De la teoría a la práctica. Madrid, Síntesis, pp. 185-215.

García Alvarado, J.M. y Sotelo Navalpotro, J.A. (1999): La España de las autonomías. Madrid, Sintesis.

García Pascual, E. (1997): Libros de texto y reforma educativa. Zaragoza, Universidad de Zaragoza.

Lacoste, Y. (1977): ¿Por qué Hérodote? Crisis de la geografía y geografía de la crisis. En Geografias, ideologias, estrategias espaciales. Madrid, Dédalo, pp. 25-66.

Lambert, D. y Balderstone, D. (2000): Learning to teach geography in the secondary scbool. London, Routledge Falmer.

Long, M. y Roberson, B.S. (1979): El uso de las fotografías en la enseñanza de la geografía. Didáctica Geográfica, 4, pp. 19-34.

Marrón Gaite, M.J. (1990): La educación de la orientación espacial en el niño a través de un juego de simulación: El tesoro de los piratas. En Primeras jornadas de didáctica de la geografía. Valencia, Asociación de Geógrafos Españoles, Grupo de Didáctica, pp. 114-118.

Marrón Gaite, M.J. (1991): Desarrollo de actitudes positivas hacia el medio ambiente a través de un juego de simulación. En II jornadas de didáctica de la geografía. Burgos, Asociación de Geógrafos Españoles, pp. 163-168.

Marrón Gaite, M.J. (1999): La geografía del comportamiento y de la percepción. Aportaciones a la investigación y a la enseñanza de la geografía. Didáctica Geográfica, $2^{\mathrm{a}}$ época, 3, pp. 85-108.

Martínez Bonafé, J. (1995): Interrogando al material curricular. (Guión para el análisis y la elaboración de materiales para el desarrollo del curriculum). En Libros de texto y construcción de materiales curriculares. Granada, Proyecto Sur de Ediciones, pp. 221-240.

Moreno Jiménez, A. y Marrón Gaite, M.J., eds. (1996): Enseñar geografia. De la teoria a la práctica. Madrid, Síntesis.

Ochaite Alderete, E. (1983): La teoría de piaget sobre el desarrollo del conocimiento espacial. Estudios de psicologia, 14-15, pp. 93-108.

Piaget, J. e Inhelder, B. (1981): Psicología del niño. Madrid, Morata

Richardson, H.W. (1986): Economia regional y urbana. Madrid, Alianza Editorial.

Rubio Benito, M.T. (1996): El vídeo didáctico y la televisión educativa. Didáctica Geográfica, $2^{\mathrm{a}}$ época, 1, pp. 35-43.

Sánchez Ogallar, A. (1996): El trabajo de campo y las excursiones. En Moreno Jiménez, A. y Marrón Gaite, M.J., eds.: Enseñar geografía. De la teoría a la práctica. Madrid, Síntesis, pp. 159-184.

Sánchez Sánchez, J. (1996): Recursos didácticos para una enseñanza renovada de la 
geografía. Didáctica Geográfica, $2^{\mathrm{a}}$ época, 1, pp. 7-13.

Sancho Comins, J. (1980): Las diapositivas, instrumento de gran valor didáctico para la enseñanza de la geografía. Didáctica Geográfica, 6, pp. 47-54.

Santos Preciado, J.M. (1996): Recursos informáticos y enseñanza de la geografía. Didáctica Geográfica, $2^{a}$ época, 1, pp. 5765.
Valverde Ortega, J.A. (1990): Algunas consideraciones sobre la utilización de mapas, croquis, planos y fotogramas en la EGB y el BUP. En Primeras jornadas de didáctica de la geografía. Valencia, Asociación de Geógrafos españoles, Grupo de Didáctica, pp. 131-134.

Zárate Martín, M. el al. (1982-83): La utilización del cine en la enseñanza de la geografía. Didáctica Geográfica, 10-11, pp. 83-98. 